\title{
Affordable Health Care
}

\author{
Manouchehr Mokhtari ${ }^{1}$
}

Published online: 10 May 2016

(c) Springer Science+Business Media New York 2016

Affordable health care ought to be ubiquitous and responsive to changes in consumer demand. Providing affordable health care by reducing out-of-pocket costs (OOPC), and encouraging prevention, maintenance, and promotion of health are essential elements of promoting the health of nation. However, what stands in the way is the daunting complexity of health care system that it is supposed to serve patients with various socioeconomic status (SES).

Health care products and services are complex and often complementary (not substitute) in nature and can only be valued by the patient's "experience" and/or by the "credence" by which they are offered. ${ }^{1}$ In other words, the health care market deviates from the competitive norm. ${ }^{2}$ Uncertainties with the timing and the nature of health care needs have led to an all-pervasive and thriving health insurance industry, entrenched regulators in each state and the federal level, and evasive providers who possess complicated incentive structures that are yet to be fully understood by scholars and/or policy makers. The outcome is an evolving spectrum of opaque prices for the complex and complementary health care products and services. Thus, nationwide experiments, strategic inputs, and academic investigations into the taming, treating, and curing an obese health care industry have become the urgent preoccupation of the government (e.g., ACA 2010), strategists (e.g., Porter and Teisberg 2006), and scholars (e.g., papers in this issue). While no specific solution is in sight, the breadth of ideas, scholarship, and evolving experiments are encouraging.

Manouchehr Mokhtari

mokhtari@umd.edu

University of Maryland, College Park, MD, USA
In the United States, the health care spending is projected to reach almost $20 \%$ of GDP by 2024, indicating a growth of an almost $6 \%$ per year. ${ }^{3}$ While, in recent years the growth rate in health care costs has been reduced, per capita spending on health care was $\$ 9,523$ in $2014 .^{4}$ In comparison, the United Kingdom, France, and Germany are spending around $8-10 \%$ of their GDP on the health care. Rising health care costs hinders access to affordable health care. Innovative solutions require an in-depth understanding of the underlying problems. This is not possible without evidence-based supported theories that assist scholars to properly frame the underlying complex issues. Theories such as the "disease cost" theory of Baumol and Bowen (1966) that relates low productivity in health sector to rising costs are helpful, but lack reference to institutions, legacies, and existing complex incentive structures in a heavily regulated health care industry. On the other hand, theory-rich solutions (e.g., Mokhtari et al. 2015) are yet to be put to the test by evidence teased from national- or international-wide databases. Understanding institutions and their legacies, which underpin the current framework for managerial input and policy analysis, is the key in gaining insight into the United States health care

\footnotetext{
${ }^{1}$ See Nelson (1970) on information and consumer behavior.

2 Arrow's (1963, p. 941) main concern was with medical care (not health) and the way "...the operation of the medical-care industry and the efficacy with which it satisfies the needs of society differ from a norm...," when the norm is defined by the operation of competitive (free market) model.

${ }^{3}$ CMS (2014), National Health Expenditure Projections 2014-2024 Forecast Summary. Retrieved from https://www.cms.gov/ResearchStatistics-Data-and-Systems/Statistics-Trends-and-Reports/National HealthExpendData/Downloads/proj2014.pdf.

${ }^{4}$ See https://www.cms.gov/research-statistics-data-and-systems/statis tics-trends-and-reports/nationalhealthexpenddata/nhe-fact-sheet.html.
} 
system, which has deviated from both the competitive norms and the international scales.

A patient-centered health care system should enable patients to act as sovereign consumers, but a health care industry that is rationalized by its legacy of dysfunction makes this evolution slow and challenging. While a desirable free market solution for the health care industry is yet to be invented, introducing competition into the existing system will help-health insurance marketplaces or health exchanges that were instigated by the ACA allow consumers to research all their options and then buy health insurance. Reducing the pitfalls of regulatory capture (Stigler 1971; Mokhtari et al. 2015), and empowering patients with transparent pricing of product and services (Mokhtari and Ashtari 2012) are both fundamental and the least intrusive aspect of good governance.

\section{Forthcoming Challenges in Affordable Health Care}

While Dolan and Mokhtari (2013) focused on pros and cons of the ACA, this Special Issue focuses on understanding those factors that influence health status and/or make health care more affordable.

In the last few years, the ACA has made health care more affordable by expanding health insurance coverage to those without it and introducing a degree of competition in the health insurance market. However, the ACA will face significant headwinds in 2017. The Waiver for State Innovation Section of the ACA (section 1332) will massively enhance the role of states' regulators and licensors in 2017. This will allow each state's regulator to alter the ACA in a profound manner. At the first blush, devolution of power to states appears as an appropriate approach for tailor making the ACA to their needs. On the other hand, a captured regulator at the state level may have incentive to take initiatives that limits competition within the state and between his/her state and other states. The current arrangement, where, the state regulator limits the patients' ability to purchase health insurance from carriers not licensed in the state, is an indication of potential headwinds that the ACA may encounter in 2017.

An important component of health care cost is the high health insurance premium that consumer has to pay. Health insurance market is highly concentrated in the United States. The Government Accounting Office report (GAO 2009) shows that the five largest health insurance carriers represented three quarters or more of the market in 34 states and that they represented $90 \%$ or more in 23 of these states. ${ }^{5}$ Patients in one state are not allowed to buy (comparable)

\footnotetext{
5 Also, see Austin and Hungerford (2010).
}

affordable health insurance in another state. One regulator in each state issues (or limits) licenses for health insurance carriers interested in operating in that state. The state regulators have the monopolistic power to effectively make judgements on limiting competition; thus, they are subject to capture by the insurance industry (Mokhtari et al. 2015). What if there are two independent regulators per state that are able to license health insurance carriers? In this case, one might argue that introducing inter-jurisdictional competition among health insurance licensors (within a state or between states) can have strong pro-patient effect, thus, making health care more affordable.

If the state regulators are truly captured, then for increasing the state's health insurance industry's profits (carrot), the regulator restricts the number of health insurance carriers. But, in a democracy, patients acting as consumers are able to wield some power (stick) over the regulator to provide him/her with an incentive to keep the premiums low. However, educating, organizing, and enticing patients to vote is an expensive proposition. On the other hand, allowing for an additional regulator within the same state (jurisdiction) or across the state lines (inter-jurisdictions) is more feasible and might have profound pro-patient effect. This is due to the fact that, in this case, both health insurance carriers and patients (consumers) might be characterized by their "virtual mobility" within or between the states. Hence, the "exit" option represents a credible bargaining strategy against the offending regulator who limits competition (which is an antidote to rising costs).

Using a non-cooperative strategic framework, it can be shown that introducing rivalry among regulators of the health insurance industry adds an inter-jurisdictional dimension to the problem of making health care affordable. This inter-jurisdictional dimension improves the state of endogenous policy making and consequently benefits the patients (without requiring them to vote). If $N$ identical health insurance carriers operate in one state, then the industry's profit in that state is $N$ times profit of each carrier $\pi$, or $N \pi$. But $\pi$ is inversely related to $N, \frac{\partial \pi}{\partial N}<0$. A regulator whose utility is fully aligned with that of state's health insurance industry's profit would allow for only one insurance company, $N=1$, to operate within his/her state. If we allow for one more competing regulator in the same state, holding the opposing regulator's action fixed, each regulator wants to issue one more license (adding one more insurer) because this increases his/her share of the spoils more than it counteracts that. In this dynamic strategic game with two independent regulators $(i=1,2)$ sharing the same jurisdiction, the optimum number of licensed insurance carriers per regulator $N_{\mathrm{i}}$ may be determined: Given the second regulator's choice $N_{2}$ of the number of insurance carriers, the first regulator drives utility from 
issuing one more license $N_{2}+1$, while ignoring the negative impact on the total profit within the industry, i.e., $N_{1} \mid N_{2}=N_{2}+1$. Second regulator's best response is similar to the first regulator, i.e., $N_{2} \mid N_{1}=N_{1}+1$. Thus, this dynamic leads to issuing as many licenses as there are insurance companies, which is an outcome of an unhindered competitive market, where patients enjoy their consumer sovereignty.

To improve consumer sovereignty, the government must use its comparative advantage in improving the consumers' basic knowledge of the health care products and services, providers, payers, and consumers' own finances. While the government's effectiveness is often attributed to regulating, mandating, financing, and providing health care, its greater role might be providing information, literacy and education to the potential patients. In a health care market rife with externalities, each unit of knowledge carries a premium that may translate into an important cost reduction opportunity for the consumers. However, patients with low-SES (such as education, occupation, and income) lacking full access to health care do not act as sovereign consumers and often incur higher health care costs than others. Improving the patients' health literacy may have three important impacts: (i) reducing inefficiency and fraud, which is as high as $26 \%$ of national expenditure (Berwick and Hackbarth 2012); (ii) increasing consumption of the health care services by the low-SES patients; and (iii) reducing poverty. In fact, a review of literature indicates the recognized effect of information and mass media on behavior, especially, on fraud, on the politicians, and on reducing OOPC (Cadot 1987; Berninghaus et al. 2010; Besley and Burgess 2002; Mokhtari and Ashtari 2012).

\section{Contributions to Affordable Health Care}

Despite the fact that the policy debate on health care reform is mainly concerned with the providers, payers, and the government actions, individuals and families are the most important decision makers about their own health (Grossman 1972; Becker 1978). Thus, a weakening of family and/or individual accountability, which results from the expansion of public role in providing health care, may inadvertently contribute to higher health care costs and higher likelihood of failure in achieving the desirable health outcomes for the nation. Accordingly, this Special Issue of the Journal of Family and Economic Issues includes six original papers that take different approaches to examining health care and its efficacy in the United States.

Bartholomae et al.'s (2016) study enhances our understanding of sociodemographic and environmental variables that predict initiation of health insurance literacy and its gains. Their robust health insurance literacy indicators rest on a well-defined, conceptualized, and psychometrically tested measure. Using 623 observations from 134 workshops in seven states during 2013-2014, they examined associations of sociodemographic, environmental characteristics, states approach to ACA, and health insurance literacy in a community-based health insurance literacy curriculum entitled Smart Choice Health Insurance. Bartholomae et al. found that the gains from certain health insurance literacy programs were concentrated among females, higher income individuals, and the states that support ACA. Based on this and a number of other important findings, they provide a number or recommendations for adapting and tailoring health insurance literacy opportunities that would take into account heterogeneity among the potential consumers.

Richard (2016a) investigated the association of dependent children with medical debt and its implication for the ACA. Richard noted that households with dependent children are subject to OOPC of health care spending shocks that may instigate taking up medical debt, reducing their consumption, reducing investment in their children, or selling assets. Additionally, dependent children's health care needs requiring time-intensive treatment may lead to parents withdrawing from the labor markets (resulting in unemployment), thus, losing their employer sponsored health insurance, or accepting lower wages. In this case, households are subject to health care spending shocks that may results in higher debt. Under either condition (OOPC or unemployment), while controlling for health insurance coverage and household financial resources, presence of dependent children in the household is associated with medical debt outcomes. Using panel study of income dynamics (PSID), the above conceptual framework, and a propensity score approach, Richard contributes to the broader literature on health and SES and found that the presence of dependent children "still" leads to financial burden for some families. However, Richard notes that the ACA's ten essential health benefits have positive implications for households with dependent children.

Hayes et al. (2016) conducted an exploratory study that investigated whether perception of economic strain relates to the physiological effect of maternal overweight/obesity body mass index, (BMI) and its relation to child BMI. The primary data set used consists of interviews with 432 female parents of preschoolers with low-income in five states. The low-income status was determined by association of caregivers with WIC, medical assistance, Head Start enrollment, and/or school lunch program participation. The results showed that reduced perception of economic strain may buffer the physiological effect of maternal overweight/obesity and its relation to child weight status. The authors noted that the actual and perceived role of food 
costs, economic situation, stress levels, parenting practices, maternal perceptions and biological factors intertwined to impact child's health as measured by child BMI. The authors also emphasized the need for structuring interventions to properly guide low-income families in their efforts to prevent childhood obesity. Hayes et al. highlight complexity of issues in health and provision of affordable health care when perception matters. They emphasize the need for a multidisciplinary approach and effective collaboration among various fields, such as, economics, family resiliency, genetics, human development, family studies, and nutrition behavior to respond to the underlying health care issues.

Beauchamp's (2016) main interest centers on answering "Did falling abortion costs contribute to the high rates of non-marital childbearing in the United States?" However, in the absence of an opportunity to answer this question, he exploits the effect of policies that increase abortion costs for poor women to approximate an indirect answer to this question. Beauchamp used a sample of 1859 pregnancies from the National Longitudinal Study of Adolescent Health to examine the impact of tightening abortion laws (rising abortion costs) on living arrangement among biological parents. His results indicate that removing public funding decreases (increases) likelihood of single motherhood (cohabitation) by about $13 \%$, while increasing the fraction of children living with both biological parents by 10 percentage points. While child welfare might improve by living with both parents, there are no measures for gauging quality of life of cohabiting (or married) parents. Beauchamp also reflects on the relevance of his findings on family structure, child poverty, reproductive health, and the implication or unintended consequences of access to technologies that lowers abortion costs in the current health care system.

Suh (2016) is primarily concerned with the paucity of a framework for understanding temporal burden of care and its typology. Suh used a pooled sample of 5488 individuals from the American Time Use Survey 2003-2012 (ATUS) to provide a sharper view of caregiving. Measures of unpaid care for children and adults showed that, as one may expect, the burden of caregiving heavily rests on women. For example, the results showed that more than $62 \%$ of women and less than $43 \%$ of men in prime age (25-44 years of age) provided interactive child care. However, the results also indicated that both women $(12.2 \%)$ and men $(11.6 \%)$ shared similar burden in their prime age for caregiving to the elderly. Suh emphasizes the need for improved measures of sandwich care that could help with better assessment of the costs of such care. In this context, better measures of sandwich care will clearly improve our understanding of the dynamics between the direct and the indirect costs of health care, and across individuals and families with different sociodemographic background. Suh notes that accurate measures of sandwich care responsibilities are relevant both to policy making and to health insurance markets for long-term care.

Richard (2016b), in his second contribution to this Special Issue, was concerned with the economic burden of the high prevalence of children with emotional and behavioral problems (EBP) on their mothers' hourly wages and annual earnings. Time-intensive caregiving for children with EBP have, a priori, a negative effect on their mothers' earnings. However, caregiving might be financeintensive, which incentivizes the mothers of children with EBP to increase work activities if they are single, or raise their reservation wage, if they are married. Using PSID data set, Richard pooled the two waves of the child development supplements (CDS) collected in 1997 and in 2002. Econometric analysis revealed that the likelihood of working for single mothers and their wage rate/annual earnings decreased if their children suffered from mental disorders. The results also showed that, initially, children's mental disorders were positively associated with their married mothers hourly wage rates and annual earningssupporting higher reservation wage because of the presence of father-but this association became statistically nonsignificant for annual earnings when other (omitted) characteristics were controlled for. Using his findings, Richard discusses ACA's provisions that have substantive implications for families with children who suffer from mental disorders; thus, making health care more affordable for the parents with children who suffer from EBP.

I would like to thank Elizabeth Dolan for her guidance, the authors for their contributions, and the reviewers of the manuscripts for their insightful and constructive input. Indeed, everyone was a significant component of the process for developing this Special Issue of the JFEI on Affordable Health Care.

\section{References}

Affordable Care Act (ACA). (2010). Patient Protection and Affordable Care Act, 42 U.S.C. $§ 18001$ et seq.

Arrow, K. (1963). Uncertainty and the welfare economics of medical care. American Economic Review, 53(5), 941-973.

Austin, D. A., \& Hungerford, T. L. (2010). The market structure of the health insurance industry. Washington, DC: Congressional Research Service. 7-5700. Retrieved from www.crs.gov, R40834.

Bartholomae, S., Russell, M., Braun, B., \& McCoy, T. (2016). Building health insurance literacy: Evidence from the Smart Choice Health Insurance ${ }^{\mathrm{TM}}$ program. Journal of Family and Economic Issues, 37. doi:10.1007/s10834-016-9482-7.

Baumol, W., \& Bowen, W. (1966). Performing arts, the economic dilemma: A study of problems common to theater, opera, music, and dance. New York: Twentieth Century Fund. 
Beauchamp, A. (2016). Abortion cost, separation, and non-marital childbearing. Journal of Family and Economic Issues, 37. doi:10.1007/s10834-015-9473-0.

Becker, G. S. (1978). The economic approach to human behavior. Chicago: University of Chicago Press.

Berninghaus, S., Haller, S., Krüger, T., Neumann, T., Schosser, S., \& Vogt, B. (2010). Risk attitude, beliefs, and information in a corruption game-An experimental analysis (working paper series in economic, No. 6). University of the State of BadenWuerttemberg and National Laboratory of the Helmholtz Association.

Berwick, D. M., \& Hackbarth, A. D. (2012). Eliminating waste in US health care. Journal of the American Medical Association, 307(14), 1513-1516. doi:10.1001/jama.2012.362.

Besley, T., \& Burgess, R. (2000). The political economy of government responsiveness: Theory and evidence from India. London: Suntory and Toyota International Centres for Economics and Related Disciplines, London School of Economics and Political Science.

Cadot, O. (1987). Corruption as a gamble. Journal of Public Economics, 33, 223-244. doi:10.1016/0047-2727(87)90075-2.

CMS. (2014). National health expenditure projections 2014-2024 forecast summary. Retrieved from https://www.cms.gov/ResearchStatistics-Data-and-Systems/Statistics-Trends-and-Reports/National HealthExpendData/Downloads/proj2014.pdf.

Dolan, E., \& Mokhtari, M. (2013). The Patient Protection and Affordable Care Act (ACA): Pros and cons. Journal of Family and Economic Issues, 34, 1-2. doi:10.1007/s10834-013-9352-5.

GAO. (February 27, 2009). Retrieved from http://www.gao.gov/new. items/d09363r.pdf.

Grossman, M. (1972). On the concept of health capital and the demand for health. Journal of Political Economy, 80, 223-255.
Hayes, J., Van Brackle, A., Sigman-Grant, M., \& All 4 Kids Obesity Resiliency Research Team. (2016). Influence of perceived economic strain on the relationship between caregiver BMI and child BMI. Journal of Family and Economic Issues, 37. doi:10.1007/s10834-015-9468-x.

Mokhtari, M., Abdelhamid, D., Ashtari, M., \& Shenassa, D. (2015). Do competing health insurance licensors provide pro-patient effects? International Economic Journal, 29(4), 571-596. doi:10.1080/10168737.2015.1081261.

Mokhtari, M., \& Ashtari, M. (2012). Reducing informal payments in the health care system: Evidence from a large patients' satisfaction survey. Journal of Asian Economics, 23(2), 189200. doi:10.1016/j.asieco.2011.11.007.

Nelson, P. (1970). Information and consumer behavior. Journal of Political Economy, 78(2), 311-329.

Porter, M. E., \& Teisber, E. O. (2006). Redefining health care: Creating value-based competition on results. Boston: Harvard Business Review Press.

Richard, P. (2016a). The burden of medical debt faced by households with dependent children in the United States: Implications for the Affordable Care Act of 2010. Journal of Family and Economic Issues, 37. doi:10.1007/s10834-016-9491-6.

Richard, P. (2016b). Children's mental disorders and their mothers' earnings: Implications for the Affordable Care Act of 2010. Journal of Family and Economic Issues, 37. doi:10.1007/s10834016-9486-3.

Stigler, G. J. (1971). The theory of economic regulation. Bell Journal of Economics and Management Science, 2(1), 3-21.

Suh, J. (2016). Measuring the "sandwich": Care for children and adults in the American Time Use Survey 2003-2012. Journal of Family and Economic Issues, 37. doi:10.1007/s10834-016-9483-6. 